\title{
DESENVOLVIMENTO PROFISSIONAL DE TREINADORES ESPORTI- VOS NO BRASIL: PERSPECTIVA DE APRENDIZAGEM AO LONGO DA VIDA ${ }^{1}$
}

\author{
Alexandre Vinicius Bobato Tozetto \\ Universidade do Estado de Santa Catarina, Florianópolis, Santa Catarina, Brasil \\ Larissa Rafaela Galatti \\ Universidade Estadual de Campinas, Limeira, São Paulo, Brasil \\ Michel Milistedt \\ Universidade Federal de Santa Catarina, Florianópolis, Santa Catarina, Brasil
}

\begin{abstract}
Resumo
O objetivo do ensaio é apresentar a teoria de aprendizagem ao longo da vida (JARVIS, 2006; 2007; 2008; 2009). No decorrer da vida, passamos por episódios e experiências em que incorporamos conhecimentos, habilidades, atitudes, entre outros elementos. Assim, podemos atribuir significados às novas experiências e, em um nível de reflexão crítica, inovar e qualificar a prática. Ao longo dos episódios de aprendizagem, surge a importância de considerá-los como um processo social, pois o que se aprende está interligado à sociedade e à cultura em que se vive, além de um processo idiossincrático, em que cada pessoa tem a sua biografia, a qual influencia no modo como atribuem significado aos episódios futuros. Ambos são condutores no desenvolvimento de treinadores ao longo da vida.
\end{abstract}

Palavras-chave: Desenvolvimento profissional. Aprendizagem ao longo da vida. Treinador esportivo.

\section{Introdução}

Aos pensarmos nas possibilidades de aprendizagem no esporte, estas podem agregar aos treinadores um amplo repertório de conhecimentos, elevar a qualidade da prática, integrar o conhecimento com a realidade contextual na qual estão inseridos e, por fim, sustentar a aprendizagem de seus atletas durante a prática esportiva (MALLETT et al., 2009; IBÁÑEZ et al., 2013). Contextos que assumem diferentes configurações e personagens, em que a aprendizagem não inicia e é finalizada exclusivamente dentro de uma estrutura de ensino formalizado, mas ocorre devido aos esforços contínuos nas vivências ao longo da vida, o que nos leva a refletir criticamente sobre as experiências diárias (JARVIS, 2006; 2009; IBÁÑ̃EZ et al., 2013; FENOGLIO, TAYLOR, 2014).

O entendimento desse processo de desenvolvimento contínuo de treinadores pode ser apresentado como a capacitação por meio dos vários processos pelos quais os profissionais

\footnotetext{
${ }^{1} \mathrm{O}$ presente trabalho não contou com apoio financeiro de nenhuma natureza para sua realização.
} 
passam por novas experiências e reconstroem suas concepções acerca do treinamento esportivo (MALLETT et al., 2009; PEEL et al., 2013). A profundidade dessa reconstrução depende do que Jones, Armour e Potrac (2003) e Nelson et al. (2013) indicam: para o desenvolvimento de habilidades de treinadores esportivos, o ato de praticar ou experimentar é necessário e, para maior relevância e relação com a realidade, é fundamental proceder na dimensão cognitiva e afetiva, bem como fazer emergir a inter-relação entre o conhecimento, o sentimento e a habilidade.

Desse modo, a partir da estrutura teórica exposta, a proposta deste ensaio é de apresentar o desenvolvimento profissional de treinadores com base na teoria de aprendizagem ao longo da vida de Peter Jarvis, na qual se considera as experiências ao longo da vida. Para isso, são apresentados diversos estudos no acompanhamento dos treinadores esportivos ao longo da vida, de modo a considerar um corpo teórico que consiga abranger uma gama de episódios em que ocorre a aprendizagem no atual cenário esportivo no Brasil.

\section{Peter Jarvis}

\section{Breve biografia do autor}

Peter Jarvis é professor na Universidade de Surrey (UK), sendo internacionalmente renomado como um expert por seus estudos desde a década de 1980 nos campos da aprendizagem ao longo da vida, da aprendizagem de adultos e da formação contínua. É membro honorário de associações profissionais em diversas partes do mundo. Ele também é palestrante em vários aspectos da educação de adultos, ensino à distância e aprendizagem ao longo da vida em todo o mundo.

Considerado como um pioneiro na área de educação para adultos, ao considerarmos seu primeiro livro publicado em 1983, Adult and continuing education: theory and practice, Jarvis ainda contribui para e reforça o conceito de aprendizagem como um processo que ocorre ao longo da vida, o que pode ser verificado em sua recente trilogia publicada: Towards a comprehensive theory of human learning (Volume 1); Globalization, lifelong learning and the learning society (volume 2); Democracy, lifelong learning and the learning society (volume 3). Além de livros mais recentes como Learning to be a person in society e outras publicações como capítulos de livro e artigos.

\section{Teoria de aprendizagem ao longo da vida}

A aprendizagem corresponde à totalidade de experiências episódicas percorridas ao longo da vida, representadas em diferentes caminhos que podem resultar na aquisição de novos conhecimentos, instruções, mudança no ser e maior experiência. Caso a pessoa não compreenda uma experiência, ocorre a chamada disjuntura, em que nos sentimos desorientados ou não conseguimos resolver essa nova experiência e, no momento em que damos um significado a ela e encontramos uma resposta, resolvemos a disjuntura. Nesse momento, voltamos ao estado de harmonia e nos tornamos mais experientes. Vale destacar que, se a pessoa não resolver a disjuntura, pode se conformar e viver com essa desorientação (JARVIS, 2006; 2009).

Aprender, então, é um processo complexo e contínuo de transformar as experiências pessoais e profissionais em uma variedade de formas, conforme a reflexão, a ação, a emoção ou qualquer combinação delas, e integrar os resultados em nossas biografias pessoais, o que nos transforma e nos torna mais experientes. Isso sempre ocorre dentro de um contexto social e cultural (JARVIS, 2008). A aprendizagem, então, é o produto de determinada cultura, a qual tem significados e símbolos particulares que compõem sua própria organização. A cultura colabora para o que se aprende em determinado contexto e a partir dele (JARVIS, 2008; 
2009). Assim, a aprendizagem deve ser compreendida como um processo social. A socialização prevalece em nossas experiências por vivermos relações interpessoais. Nenhuma pessoa é uma ilha, a realidade globalizada nos reporta além das experiências variadas diárias, ampliadas pelos meios de comunicação em todo o mundo e esta é a natureza da experiência humana (JARVIS, 2006). Essas oportunidades de aprendizagem possibilitam expandirmos nossas capacidades mentais e evoluirmos (JARVIS, 2006; 2009).

Desse modo, para uma definição que possa contemplar a aprendizagem humana, esta é compreendida por Jarvis (2009, p.35) como:

[...] a combinação de processos ao longo da vida pelos quais a pessoa inteira - corpo (genético, físico e biológico) e mente (conhecimentos, habilidades, atitudes, valores, emoções, significados, crenças e sensações) - experiencia situações naturais e sociais, cujo conteúdo é então transformado cognitivamente, emotivamente ou empiricamente (ou por meio de qualquer combinação dessas formas) e integrado à biografia individual da pessoa, resultando em uma pessoa em constante mudança (ou mais experienciada).

A "emoção" no decorrer desse aprendizado e sobre o comportamento humano desempenha um papel importante, uma vez que está no centro de nossa personalidade e influencia na forma como respondemos cognitivamente e na questão comportamental (JARVIS, 2006; 2009). A "reflexão" pode ser verificada no último nível de aprendizagem na classificação de Jarvis (2006), na qual o indivíduo por dar significado a sua experiência e por isso ocorre um maior aprendizado, conforme segue: (i) não aprendizagem, em que os indivíduos simplesmente não consideram, rejeitam ou presumem que a experiência é óbvia e não aprendem; (ii) aprendizagem não reflexiva, nível superficial de aprendizagem, pré-consciente, em que os indivíduos, pela baixa consciência, acabam aprendendo alguma coisa na prática, por aprender habilidades básicas sem refletir e pela memorização; (iii) aprendizagem reflexiva, nível mais profundo de aprendizagem, por contemplação, em que o indivíduo passa por uma situação, reflete sobre ela e aceita ou modifica sua experiência. A prática reflexiva implica uma ação imediata diante da situação, em consonância com ela ou inovando em relação a ela. Por fim, na aprendizagem experiencial, os indivíduos passam por uma situação e pensam sobre o episódio, para concordar ou discordar do que experienciaram (JARVIS, 2006). Em resumo, a "ação" de aprender é uma necessidade do indivíduo e também social; para aprender a ser e incluir-se como membro da sociedade, o sujeito não vive nela, mas participa e contribui para o crescimento e o desenvolvimento de outras pessoas, o que ocorre nas ações vividas diariamente (JARVIS, 2006; 2008; 2009).

As três formas (emoção, ação, reflexão), combinadas de modo intenso, em que o indivíduo atribui sentimentos, reflete e age sobre a experiência, podem conduzir ao maior aprimoramento das suas habilidades e dar um novo significado a uma determinada socialização e experiência. Isso pode levar a uma maior sabedoria e desenvolver a expertise desses "atores" (JARVIS, 2006).

\section{As socializações e experiências de aprendizagem}

A aprendizagem inicia em participações descritas como socialização primária, nas relações com familiares. Por exemplo, quando participamos dos primeiros episódios de vida e acumulamos conhecimentos, habilidades, atitudes, crenças, que conduzem a forma como nos inserimos na sociedade. A socialização secundária ocorre no envolvimento com outros grupos, na escola, no trabalho, no esporte, os quais levam a interações e ao compartilhamento de diferentes culturas nos diversos episódios de aprendizagem ao longo da vida (JARVIS, 2008). 
Dentre os episódios de aprendizagem, as experiências são concentradas por Jarvis (2008) em dois momentos: experiências primárias e experiências secundárias. A respeito das experiências primárias, são descritas quando se fazem associações por meio dos sentidos e são incorporadas pela reflexão e pela interação com os outros, em uma construção de significados a partir das respostas pessoais - cognitivas e emocionais (JARVIS, 2008). O autor explica que, ao sentirmos um odor, podemos saber sua origem, se provém de flores ou de uma fábrica, e o mesmo ocorre com os outros sentidos. As ações diárias consistem em experiências primárias a que respondem em uma ampla variedade de formas, por meio das quais buscamse significados.

As experiências secundárias seriam situações em que a cultura é compartilhada. Por meio das interações, as experiências são narradas e experienciadas, desse modo, ao mesmo tempo em que a interação é uma experiência primária, o discurso é secundário. As teorias aprendidas na universidade são consideradas experiências secundárias ou mediadas, além de outras situações mediadas no processo de ensino-aprendizado. Contudo, as interpretações das experiências e as transmissões precisam ser apreciadas criticamente (JARVIS, 2008).

\section{Os episódios de aprendizagem do treinador esportivo}

Conforme explica Jarvis (2006), as aprendizagens ocorrem em meio a uma sucessão de episódios de aprendizagem, classificação que compreende como sendo um processo idiossincrático, social e contínuo por meio das experiências. Cada experiência nos diferentes episódios de aprendizagem pode agregar conhecimentos, habilidades, entre outros componentes na biografia do indivíduo, para que possam dar significado às novas experiências sociais e responder a uma determinada disjuntura ou influenciar no que se aprende em experiências futuras. Para o autor, o que é aprendido em um episódio (formalizado ou não formal) pode se sobrepor ao que é aprendido em outro episódio (informal ou qualquer outro), mas não podemos demonstrar essa complexidade pelo fato de a aprendizagem não ser compreendida em sua totalidade por conta da natureza diversa (participação em diferentes grupos sociais e conhecimento de novas culturas) das experiências ao longo da vida.

Em complementação, os diferentes episódios de aprendizagem são importantes no sentido de transformar os treinadores em sujeitos ativos na construção do próprio conhecimento, na tentativa de ampliar a capacidade de intervenção (MILISTETD et al., 2015). Ao refletirmos sobre os episódios de aprendizagem no Brasil, são levantadas possibilidades de desenvolvimento profissional de treinadores, com uma visão ampliada e profunda, de modo a compreendermos os diferentes caminhos de experimentação.

\section{Episódios de aprendizagem em contextos educacionais}

Ao pensarmos na aprendizagem, recomenda-se que nenhuma das experiências (primárias e secundárias) seja excluída ou priorizada, mas, para um maior aprendizado, deve-se considerá-las conjuntamente. Assim, cabe aos educadores, no contexto universitário, ofertar experiências primárias, pela dramatização, pela simulação, entre outras manifestações, a fim de que os alunos vivenciem situações que os remetam para a prática, cognitivamente, físicamente e emocionalmente. Em decorrência disso, relacionariam as teorias que aprenderam (experiências secundárias) com o mundo real. Para Jarvis, a prática precede a teoria e, por meio de uma reflexão crítica, criamos a nossa própria teoria a partir dela, fazendo com que a aprendizagem possa ser significativa (JARVIS, 2008).

Desse modo, aos professores é recomendado conhecer seus alunos e, por meio das suas experiências primárias e secundárias, fazer com que as informações tenham significado e se tornem expressivas em sua biografia, causando uma disjuntura. Alguns exemplos experien- 
ciados pelos alunos podem ser trabalhados durante as reflexões, como a forma dos seus treinadores de conduzir os treinamentos e o que poderia ser melhorado. Tais atividades poderiam suprir as necessidades do curso e preencher lacunas, como destacado por Mesquita et al. (2014), ao entrevistarem seis treinadores experts: segundo eles, a preocupação seria o distanciamento entre a prática e a teoria. Nesse caso, os treinadores não conseguem aplicar o que discutiram na sala de aula dentro dos cursos de formação. No estudo de Milistetd et al. (2014), outro problema é apresentado, ao analisarem os currículos dos cursos de bacharelado em Educação Física. Atualmente, a formação inicial educaria para o esporte de participação e não para o de rendimento esportivo, possivelmente pela menor carga horária para o desenvolvimento da área.

Mesmo apresentando lacunas, no Brasil, os profissionais de Educação Física considerados aptos para atuação como treinadores têm a regulamentação da profissão com o intuito de delinear uma ampla formação acadêmica e com preocupações em relação ao diverso e complexo contexto de atuação, como descrito no Art. $3^{\circ}$ nas ações de coordenar, planejar, programar, supervisionar, entre outras, todas nas áreas de atividades físicas e do desporto (BRASIL, 1998). Na esfera educacional, aos cursos de nível superior como um todo, surge à necessidade de oportunizar as condições fundamentais para a maior efetividade durante a formação, o que exige conhecer e monitorar as exigências do mundo globalizado e as reais necessidades da população, para desenvolver o potencial máximo dos futuros profissionais (JARVIS, 2008). A reformulação do curso pode atender à realidade de treinamento e competição, mas também exige a motivação dos treinadores em aprender, conforme o estudo de Callary, Werthner e Trudel (2012), no qual inicialmente uma treinadora destacou que pensava não precisar de uma formação, mas, por intermédio de um curso, ficou impressionada com os conteúdos que poderiam ser aprendidos. Dentre eles, ela relata que aprendeu a estruturar programas de treinamento a longo prazo para o desenvolvimento de atletas, sobre a análise técnica e tática, além de aprender sobre procedimentos de segurança. Por isso, para Jones, Armour e Potrac (2003), emerge a necessidade de incluir componentes que reflitam sobre as influências da estrutura e a atuação no cumprimento de seus papéis, apresentadas pelo treinador diante dos problemas da vida real.

Desse modo, em meio ao processo de ensino formalizado, os futuros treinadores precisam dar significado às suas experiências, caso contrário, os conteúdos podem não impactar suas ações, principalmente se já têm uma experiência prévia que defina a sua filosofia de treinamento. Segundo alguns autores (CUSHION; ARMOUR; JONES, 2003; RAMOS et al., 2011; SCAGLIA, 2011; 2015), uma das maiores preocupações seria a repetição das experiências práticas prévias pelos alunos, repassadas de geração em geração na relação treinadoratleta baseada apenas na afetividade, ou mesmo pelo senso comum, sem uma reflexão crítica que possa compreender e transformar estas importantes experiências.

\section{Episódios de aprendizagem em contextos não formais}

No episódio não formal, emerge a importância da liberdade e da oportunidade de o indivíduo aprender continuamente, sendo que a educação para adultos na graduação permanece subfinanciada e não é direito de todos (JARVIS, 2007).

Nos achados de Christensen (2014), os cursos de curta duração apresentaram potencialidades, em que o período formativo gerou um impacto na consciência dos papéis e estilos de treinamento dos treinadores. Um treinador de alto rendimento relata que aprendeu sobre comunicação, liderança e psicologia do esporte. Além disso, o episódio de aprendizagem não formal, possivelmente por ocorrer em um círculo social específico com um interesse comum, faz com que os treinadores apresentem maior motivação e iniciativa para o aprendizado, pelo fato de que os participantes passam por diferentes abordagens de ensino, em situações e rela- 
ções pessoais distintas, as quais podem elevar a reflexão crítica e criativa para transformar o ambiente positivamente (NELSON; CUSHION; POTRAC, 2006; CUNHA et al., 2010; NELSON et al., 2013; FENOGLIO; TAYLOR, 2014; MILISTETD et al., 2014; BRASIL et al., 2015).

Os episódios em contextos não formais têm essa natureza de compartilhamento de informações e esclarecimentos em relação aos conteúdos específicos apresentados, entre os profissionais de diferentes contextos de treinamento, o que pode facilitar a compreensão por parte dos treinadores (NELSON; CUSHION; POTRAC, 2006; MALLETT et al., 2009). Dessa forma, o episódio de aprendizagem não formal pode representar um contexto relevante aos treinadores devido às intensas relações sociais de aprendizagem, o que pode complementar o que foi experienciado superficialmente, o que não foi compreendido ou não experienciado no caso dos provisionados (apresentado no próximo tópico) no curso de bacharelado em Educação Física.

Portanto, o episódio não formal configura-se como uma forma de ampliar a rede de relacionamentos com diferentes grupos e personagens (outros treinadores, preparadores físicos, profissionais de outras áreas, entre outros), o que pode gerar um aprendizado significativo. Por isso, políticas como a oferta de cursos pela Academia Brasileira de Treinadores e confederações são importantes para agregar os provisionados no campo científico e capacitar continuadamente os profissionais graduados. Entretanto, cabe aos treinadores refletir criticamente sobre cada experiência e considerar o que for positivo para o seu contexto.

\section{Episódios de aprendizagem em clubes e no ambiente virtual}

Ao se falar sobre as experiências de aprendizagem, Jarvis destaca que algumas podem ser mais significativas que outras (JARVIS, 2006). Na formação de treinadores, os episódios de aprendizagem informais, por estarem associados ao maior interesse no aprendizado, são apontados em diversos estudos como prática expressiva à realidade profissional, sendo motivadora nos episódios de aprendizagem e fazendo com que os profissionais se envolvam consideravelmente. O papel dos treinadores mais experientes nesse processo é essencial na conduta de práticas educativas claras para transmitir os conhecimentos necessários para o desenvolvimento profissional (TRUDEL; CULVER; WERTHNER, 2013; FENOGLIO; TAYLOR, 2014; RAMOS et al., 2014).

Nesse processo, as ações pedagógicas, entre outros conhecimentos, podem, conforme Ramos e colaboradores (2011), ser determinadas pelas experiências práticas, como no período em que os treinadores foram atletas. No Brasil, a resolução CONFEF n ${ }^{\circ}$ 045/2002, dispõe sobre o registro de não graduados em Educação Física no Sistema CONFEF/CREFs. Em seu Art. $2^{\circ}$, é disposto ao requerente apresentar comprovação oficial da atividade exercida, até a data do início da vigência da Lei no 9696/98, por prazo não inferior a três anos.

Nestas diversas atividades, são oportunizadas experiências de aprendizagem, seguindo de acordo com uma determinada tendência sociocultural. Contudo, cabe prioritariamente aos treinadores a iniciativa de refletir sobre as fontes de aprendizagem para progredir na carreira profissional, aperfeiçoar os treinamentos e o desempenho competitivo cada vez mais próximo de ações eficazes, de modo a alcançar maior valorização e autonomia por parte de seus atletas (RAMOS et al., 2011; SCAGLIA, 2011, 2015; IBÁÑEZ et al., 2013; RESENDE, 2013).

A seguir são destaques, conforme descritos por Jarvis (2007), a internet, como um ambiente virtual de aprendizagem no atual "mundo globalizado", em que pessoas de diversos locais ou países podem interagir instantaneamente, e a "organização de aprendizagem", no caso os clubes esportivos, como possíveis potencializadores da aprendizagem profissional. 


\section{A aprendizagem no mundo virtual}

Na contemporaneidade, a internet é um dos meios de comunicação em massa sobre o fenômeno esportivo, com grande capacidade e velocidade na atualização dos mais variados assuntos, com a vantagem de, nela, ter-se a chance de ler, escutar e assistir a vídeos, disponibilizados instantaneamente de qualquer lugar do mundo (SILVA et al., 2014). Por esses motivos, a busca de novos conhecimentos na internet pelos profissionais ganha força nessa atual configuração de mundo conectado (JARVIS, 2007; TRUDEL; CULVER; WERTHNER, 2013). Nessa era globalizada, cabe aos treinadores exercerem um senso crítico em relação aos conteúdos disponibilizados no ambiente virtual para reavaliar a sua prática. Conteúdos que não necessariamente devem ser copiados, mas podem ser utilizados como fonte inspiradora da criatividade, considerando as particularidades (idade maturacional, sexo, habilidades) de seus atletas.

\section{A “organização de aprendizagem"}

Considerando que somos seres em constante mudança (JARVIS, 2009), o clube também pode fornecer continuamente aos seus profissionais experiências que resultem em novos conhecimentos. Ao se sistematizar essa abordagem, pode-se passar a caracterizá-la como real "organização de aprendizagem", por envolver e engajar, neste caso, os treinadores em atividades contínuas de capacitação para a prática. A aprendizagem, então, pode ser potencializada e não ocorrerá apenas de forma imprevisível.

Jarvis (2007) explica que grande parte do que aprendemos não é controlado ou planejado, ou ambos. Assim, torna-se essencial que as organizações, como os clubes, encorajem os treinadores a aprender ininterruptamente, incentivo que, segundo o autor, ocorre geralmente em organizações com propósitos vocacionais, como nas universidades. Nesse sentido, os líderes de grandes organizações, reconhecendo a necessidade de mudar, precisam considerar que a eficácia depende de que as pessoas dentro das organizações compartilhem suas experiências com os outros, como no caso dos profissionais mais experientes repassando aos mais novos a sua função e não ficando presos à competitividade. Mesmo assim, no estudo de Mesquita e colaboradores (2014), treinadores de diversos esportes classificaram os ambientes de treinamento na maior parte do tempo como de "concorrência em vez de colaboração".

Para a complementaridade dessas ações, Talamoni, Oliveira e Hunger (2013) e Galatti et al. (2014) observam que o trabalho com os jogos esportivos coletivos vai além do auxílio entre os treinadores ou das conversas entre a comissão técnica, mas que depende de uma equipe multidisciplinar. $\mathrm{O}$ treinador tem uma maior preocupação com relação aos componentes técnico-táticos e o preparador, com a parte física dos atletas. Fora de campo, o nutricionista é o responsável pela alimentação e pela reposição energética e o psicólogo, pela motivação e pela resiliência dos atletas. Apesar da grande dificuldade no trabalho objetivo de cada especialidade, é importante a intersubjetividade entre os profissionais e com os atletas.

\section{A prática reflexiva como componente da aprendizagem}

A reflexão como uma necessidade para a aprendizagem motivadora e significativa pode ser fundamentada e aprimorada após cada experiência (JARVIS, 2006) e normalmente é fomentada pelas discussões com atletas, comissão técnica, psicólogos, organizadas de acordo com as estratégias assumidas pelos treinadores, como a utilização de vídeos, áudios, relatórios, dentre outros, para posterior análise reflexiva (GILBERT; TRUDEL, 2001; 2005; CASSIDY; JONES; POTRAC, 2009; GALATTI et al., 2014). 
O fato de os treinadores passarem pelos diversos episódios de aprendizagem, conforme apresentados anteriormente, e levando em consideração as dimensões descritas por Jarvis (2006), estado emocional e atitudes no momento da experiência, ressalta a importância de desenvolverem suas competências e capacidades por meio de uma reflexão (terceira dimensão descrita por Jarvis, 2006) estruturada para que questionem as informações a serem personificadas. Caminho de inquietações que pode não ser fácil aos treinadores, por envolver transformações em um ambiente com crenças absolutas na prática (KNOWLES et al., 2006; PEEL et al., 2013).

Além das crenças, os treinadores ainda passam por outras dificuldades na reorganização da prática. A utilização de um tempo excessivo para a reflexão pode ocasionar perda do fluxo da ação. Essa dificuldade pode ser decorrente da necessidade de mudança de comportamento, em que os treinadores apresentem uma nova forma de intervenção aos seus atletas posteriormente à verificação de falhas na conduta da preparação esportiva. Outro fator seria o período de familiarização com as expectativas, direitos e responsabilidades decorrentes do novo método (CASSIDY; JONES; POTRAC, 2009). Para os treinadores investigados por Egerland et al. (2013), uma das necessidades profissionais percebidas foi a habilidade de realizar uma autorreflexão e reformular os métodos de treinamento utilizados. Desse modo, Gilbert e Trudel $(2001 ; 2005)$ acreditam ser fundamental diferenciar o processo reflexivo dos treinadores em três momentos. A reflexão na ação é um processo tácito e inseparável da prática, enquanto a reflexão para a ação é um processo consciente. O sujeito dispõe de tempo para organizar sua reflexão, como na elaboração de um plano de trabalho, e, no terceiro momento, realiza-se a retrospectiva da reflexão sobre a ação, quando o treinador avalia suas experiências passadas.

As propostas dos autores reportam que a reflexão se caracteriza como essencial para melhores práticas. Por ser um processo complexo, pode apresentar como auxílio o uso de ferramentas (vídeos de seus comportamentos, diários reflexivos) e ações sistematizadas (reflexões em grupo ou individualizadas). Processo que pode se iniciar no contexto educacional, no momento em que os alunos ainda não têm a responsabilidade real de um treinador e, por isso, a sua experimentação pode ocorrer mais facilmente, na realização de reflexões e mudanças em suas atitudes com maior confiança e no sentido de que cada vez mais consigam responder em um menor período de tempo aos problemas da prática. Além disso, no momento em que assumem a função, conseguir antecipar situações, quando os profissionais visualizam as necessidades de seus atletas e se organizam antecipadamente para supri-las.

\section{Considerações finais}

O objetivo deste ensaio foi apresentar o desenvolvimento profissional de treinadores com base na teoria de aprendizagem ao longo da vida de Peter Jarvis (2006; 2007; 2008; 2009). A aprendizagem se constitui em um universo de possibilidades, no qual os treinadores adquirem aprendizagens ao longo da vida e podem aumentar seu repertório de ações no processo de ensino-aprendizagem-treinamento. Ao concentrarem esses aprendizados, os treinadores podem responder a uma disjuntura e compreender seus atletas, os conteúdos de treinamento e a cultura do esporte.

A aprendizagem dos treinadores, então, ocorre desde o nascimento, nos episódios com a família, definidos por Jarvis como socialização primária, em que começam a incorporar experiências e aprendizados sobre o que é necessário para viver em sociedade e sobre uma cultura particular que pode ser relacionada ao esporte. Posteriormente, a aprendizagem segue em meio à socialização secundária, como nos episódios em que os treinadores podem ter sido atletas e conhecem novas culturas. Neste caso, podem aprofundar os aprendizados experienci- 
ados na socialização primária, especificamente sobre o esporte ou uma modalidade esportiva, individual ou coletiva, em específico.

Nos episódios de aprendizagem formalizados e não formais, recomenda-se aos professores, facilitadores ou instrutores conhecer seus alunos por meio de conversas, trabalhos acadêmicos, entre outros instrumentos, e considerar as suas experiências na socialização primária com seus familiares, que podem apresentar uma forte relação com o esporte, e na socialização secundária, como na participação como atletas, para relacioná-las de modo a dramatizar e dar um significado aos conteúdos de ensino. Assim, os alunos podem responder mais facilmente às suas disjunturas e começar a criar uma autonomia sobre o conhecimento e as competências relacionados ao esporte.

Após a realização do curso, sugere-se em outros contextos, como no clube, o suporte aos treinadores para que a aprendizagem seja um processo sistematizado e contínuo, ao invés de ocorrer ao acaso. O intuito seria de aprender com o outro e perceber a própria prática de outra perspectiva e, assim, evitar ou extinguir possíveis comportamentos negativos e não aceitar a disjuntura como um processo habitual. A internet, como um novo veículo de compartilhamento de informações, disponibiliza diversos conteúdos de treinamento e cabe aos treinadores decidir o que é relevante para a sua prática.

Para que as experiências nos três episódios de aprendizagem tenham significado e apresentem um maior aprendizado, uma estratégia seria sistematizar a reflexão crítica e criativa, ininterruptamente, com o intuito de que os futuros treinadores consigam controlar suas emoções e atitudes por meio de uma reflexão profunda. Em consequência, executar seus treinamentos com maior qualidade, por meio das avaliações de seus atletas, adversários, atividades e conteúdos de treinamento e sobre a sua própria filosofia de treinamento. Isso depende de um conjunto de forças entre instituições ou organizações (universidades, confederações, federações, clubes) e de seus profissionais (treinadores, professores, diretores) criar e manter uma concepção de aprendizagem aberta, com a finalidade de fomentar iniciativas por meio de planejamentos e objetivos claros, desenvolvidos a longo prazo, para uma aprendizagem significativa dos treinadores e de outros profissionais ligados ao esporte. Em suma, a aprendizagem é um processo idiossincrático e social que ocorre ao longo da vida.

\title{
SPORTS COACH DEVELOPMENT IN BRAZIL: LIFELONG LEARNING PER- SPECTIVE
}

\begin{abstract}
The aim of the essay is to present the theory of lifelong learning (JARVIS, 2006; 2007; 2008; 2009). Throughout life, we go through episodes and experiences in which we incorporate knowledge, skills, attitudes, among other elements. Thus, we can assign meanings to new experiences and at a critical reflection level, innovate and qualify the practice. Throughout the learning episodes, the importance of considering them as a social process arises, because what one learns is intertwined with the society and culture in which one lives, in addition to an idiosyncratic process in which each person has his biography, the influence on the way they attribute meaning to future episodes. Both conductors in coach development throughout life.
\end{abstract}

Keywords: Coach development. Life long learning. Sports coach. 


\section{DESARROLLO PROFESIONAL DE LOS ENTRENADORES DEPORTIVOS EN BRASIL: PERSPECTIVA DE APRENDIZAJE A LO LARGO DE LA VIDA}

\section{Resumen}

El objetivo del ensayo es presentar la teoría de aprendizaje a lo largo de la vida (JARVIS, 2006; 2007; 2008; 2009). Durante el transcurso de la vida, pasamos por episodios y experiencias en los que adquirimos conocimientos, habilidades, actitudes, entre otras cosas. De esa forma, podemos atribuir significados a las nuevas experiencias y, en un nivel de reflexión crítica, innovar y clasificarla práctica. A lo largo de los episodios de aprendizaje, surge la importancia de considerarlos como un proceso social, pues lo que se aprende está interconectado a la sociedad y a la cultura en que se vive, además de un proceso idiosincrásico en el que cada persona tiene una biografía, que influye en el modo como se atribuyen significados a los episodios futuros. Ambos son conductores en el desarrollo de entrenadores a lo largo de la vida.

Palabras clave: Desarrollo profesional. Aprendizaje a lo largo de la vida. Entrenador deportivo.

\section{Referências}

BRASIL. Lei $\mathrm{n}^{\circ}$ 9.696, de 1 de setembro de 1998. Dispõe sobre a regulamentação da profissão de Educação Física e cria os respectivos Conselho Federal e Conselhos Regionais de Educação Física. Documento Oficial da União, Brasília, DF, 1 set. 1998.

BRASIL. Resolução CONFEF no ${ }^{\circ}$ 45/2002. Dispõe sobre o registro de não graduados em Educação Física no Sistema CONFEF/CREFs. Rio de Janeiro, 18 fev. 2002.

BRASIL, V. Z.; RAMOS, V.; BARROS, T. E. S.; GODTSFRIEDT, J.; NASCIMENTO, J. V. A trajetória de vida do treinador esportivo: as situações de aprendizagem em contexto informal. Movimento, v. 21, n. 3, p. 815-829, jul./set. 2015.

CALLARY, B.; WERTHNER, P.; TRUDEL, P. How meaningful episodic experiences influence the process of becoming an experienced coach. Qualitative research in sport, exercise and health, v. 4, n. 3, p. 420-438, 2012.

CASSIDY, T.; JONES, R.; POTRAC, P. Understanding sports coaching: the social, cultural and pedagogical foundations of coaching practice. 2 ed. New York: Routledge, 2009.

CHRISTENSEN, M. K. Outlining a typology of sports coaching careers: paradigmatic trajectories and ideal career types among high-performance sports coaches. Sports Coaching Review, v. 2, n. 2, p. 98-113, 2013.

CULVER, D.; TRUDEL, P. Clarifying the concept of communities of practice in sport. International journal of sports science and coaching, v. 3, n. 1, p. 1-10, mar. 2008.

CULVER, D.; TRUDEL, P.; WERTHNER, P. A sport leader's attempt to foster a coaches' community of practice. International Journal of Sports Science and Coaching, v. 4, n. 3, p. 365-383, nov. 2009.

CUNHA, G. B. ; MESQUITA, I. M. B.; ROSADO, A . F. B. ; SOUSA, T. ; PEREIRA, P.. Necessidades de formação para o exercício profissional na perspectiva do treinador de futebol 
em função da sua experiência e nível de formação. Motriz, v. 16 n. 4, p. 931-941, out./dez. 2010 .

CUSHION, C.; ARMOUR, K.; JONES, R. Coach education and continuing professional development: Experience and learning to coach. Quest, v. 55, n. 3, p. 215-230, 2003.

EGERLAND, E. M.; SALLES, W. N.; BARROSO, M. L. C.; BALDI, M. F.; NASCIMENTO, J. V. Potencialidades e necessidades profissionais na formação de treinadores desportivos. Revista Brasileira de Ciência e Movimento, v. 21, n. 2, p. 31-38, 2013.

FENOGLIO, R.; TAYLOR, W. From winning-at-all-costs to Give Us Back Our Game: perspective transformation in youth sport coaches. Physical Education and Sport Pedagogy, v. 19, n. 2, p. 191-204, 2014.

GALATTI, L. R; REVERDITO, R. S.; SCAGLIA, A. C.; PAES, R. R.; SEOANE, A. M. Pedagogia do Esporte: tensão na ciência e o ensino dos Jogos Esportivos Coletivos. Revista da Educação Física/UEM, v. 25, n. 1, 153-162, 1. trim. 2014.

GILBERT, W.; TRUDEL, P. Learning to coach through experience: Reflection in model youth sport coaches. Journal of Teaching in Physical Education, Champaign, v. 21, p. 1634, 2001.

GILBERT, W.; TRUDEL, P. Learning to coach through experience: conditions that influence reflection. The Physical Educator, v. 32, n. 1, p. 32-43, 2005.

IBÁÑEZ, S. J. et al. Avances y desafios en la formación de los entrenadores de deportes colectivos. In: NASCIMENTO, J. V.; RAMOS, V.; TAVARES, F. (Org.). Jogos desportivos: formação e investigação. Florianópolis: UDESC, 2013. p.319-343.

JARVIS, P. Towards a comprehensive theory of human learning. London: Routledge, 2006.

JARVIS, P. Globalisation, lifelong learning and the learning society: sociological perspectives, lifelong learning and the learning society. Abingdon: Routledge, 2007.

JARVIS, P. Democracy, lifelong learning and the learning society: Active citizenship in a late modern age. Abingdon: Routledge, 2008.

JARVIS, P. Learning to be a person in society. New York: Routledge, 2009.

JONES, R.; ARMOUR, K.; POTRAC, P. Constructing expert knowledge: a case study of a top-level professional soccer coach. Sport, Education and Society, v. 8, n. 2, p. 213-229, oct. 2003.

KNOWLES, Z.; TYLER, G.; GILBOURNE, D.; LTD, F. Reflecting on reflection: exploring the practice of sports coaching graduates. Reflective Practice, v. 7, n. 2, p. 163-179, may. 2006.

MALLETT, C.; TRUDEL, P.; LYLE, J.; RYNNE, S. B. Formal vs. Informal Coach Education. International Journal of Sports Science \& Coaching, v. 4, n. 3, p. 325-64, 2009. 
MESQUITA, I.; RIBEIRO, J.; SOFIA, S.; MORGAN, K. Coach learning and coach education: Portuguese expert coaches' perspective. The Sport Psychologist, v. 28, n. 2, p. 124-36, 2014.

MILISTETD, M ; TRUDEL, P.; MESQUITA, I. ; NASCIMENTO, J. V. Coaching and coach education in Brazil. International Sport Coaching Journal, v. 1, p. 165-172, 2014.

MILISTETD, M. et al. A aprendizagem profissional de treinadores esportivos: desafios da formação inicial universitária em Educação Física. Pensar a Prática, v. 18, n. 4, 2015.

NELSON, L.; CUSHION, C.; POTRAC, P. Formal, nonformal and informal coach learning: A holistic conceptualisation. International Journal of Sports Science and Coaching, v.1, n.3, p. 247-259, sep. 2006.

NELSON, L.; POTRAC, P.; GILBOURNE, D.; ALLANSON, A.; GALE, L.; MARSHALL, P. Thinking, feeling, acting: the case of a semi-professional soccer coach. Sociology of Sport Journal, v.30, 467-486, 2013.

PEEL, J.; CROPLEY, B.; HANDON, S.; FLEMING, S. Learning through reflection: values, conflicts, and role interactions of a youth sport coach. Reflective Practice, v. 14, n. 6, p. 729$742,2013$.

RAMOS, V.; GRAÇA, A. B. S.; NASCIMENTO, J. V.; SILVA, R. A aprendizagem profissional - as representações de treinadores desportivos de jovens: quatro estudos de caso. Motriz, v. 17, n. 2, p. 280-291, abr./jun. 2011.

RAMOS, V.; BRASIL, V.Z.; BARROS, T. E. S.; GODA, C.; GODTSFRIEDT, J. Trajetória de vida de treinadores de surfe: análise dos significados de prática pessoal e profissional. Pensar a Prática, v. 17, n. 3, 2014.

RESENDE, R. Desafio na formação de treinadores de jovens. In. NASCIMENTO, J. V.; RAMOS, V.; TAVARES, F. (Org.). Jogos desportivos: formação e investigação. Florianópolis: UDESC, 2013. p. 359-383.

SCAGLIA, A. J. A formação profissional e o futebol: dilemas pedagógicos. Revista das Faculdades Integradas Coração de Jesus, v. 1, n. 1, p. 1-84, jul./dez. 2011.

SCAGLIA, A. J. A pedagogia do esporte em José Mourinho. Revista Educação e Linguagens, v. 4, n. 7, p. 16-37, jul./dez. 2015.

SILVA, R. N. B. ; TALAMONI, G. A. ; TAVARES JÚNIOR, A. C. ; CRESSONI, F. E. G.; TEBALDI, M. ; PAJANIAN, F.; OLIVEIRA, A. L. ; DRIGO, A. J. Futebol e a construção da imagem de treinadores pela mídia: um estudo a partir das notícias de um site de grande visitação na web. Revista Brasileira de Ciências do Esporte, v, 36, n.3, p. 648-655, 2014.

TALAMONI, G. A.; OLIVEIRA, F. I. S; HUNGER, D. As configurações do futebol brasileiro: análise da trajetória de um treinador. Movimento, v. 19, n. 1, p. 73-93, jan./mar. 2013. 
TRUDEL, P; CULVER, D; WERTHNER, P. Looking at coach development from the coachlearner's perspective: considerations for coach development administrators. In: POTRAC, P.; GILBERT, W.; DENISON, J. (Org.). Routledge handbook of sports coaching. London: Routledge, 2013. p. 375-387.

\section{Agradecimentos}

À Fundação de Apoio à Pesquisa Científica e Tecnológica do Estado de Santa Catarina (FAPESC) e à Fundação de Amparo à Pesquisa do Estado de São Paulo (FAPESP).

Recebido em: 30/01/2017

Revisado em: 04/08/2017

Aprovado em: 10/10/2017

Endereço para correspondência:

alexandrebobato@ hotmail.com

Alexandre Vinicius Bobato Tozetto

Universidade do Estado de Santa Catarina, Centro de Educação Física e Desportos, Departamento de Desportos

Rua Pascoal Simone, 358

Coqueiros

88080-350 - Florianópolis, SC - Brasil 